
\title{
28 Research Square \\ Experience of fatigue and related factors among HIV-infected adults attending ART clinic in Ethiopia; a cross-sectional study
}

\section{Moges Baye}

University of Gondar College of Medicine and Health Sciences

\section{Berihu Fisseha}

Mekelle University College of Health Sciences

\section{Mulugeta Bayisa Chala}

University of Gondar College of Medicine and Health Sciences

\section{Solomon Mekonnen Abebe}

University of Gondar College of Medicine and Health Sciences

\section{Balamurugan Janakiraman ( $\nabla$ bala77physio@gmail.com )}

Department of Physiotherapy, School of Medicine, College of Medicine and Health Sciences, University of Gondar and Gondar University specialized comprehensive hospital, Ethiopia https://orcid.org/00000003-3866-9351

\section{Research article}

Keywords: Fatigue, HIV/AIDS, Anti-retroviral therapy, Weight loss, Ethiopia

Posted Date: June 18th, 2020

DOl: https://doi.org/10.21203/rs.3.rs-36302/v1

License: @ (i) This work is licensed under a Creative Commons Attribution 4.0 International License. Read Full License 


\section{Abstract}

Background: Fatigue is one of the most common bothersome HIV-related morbidity. The HIV prevalence in Ethiopia is heterogeneous by sex, geographic areas, and population groups. In Ethiopia, there is a need to estimate the burden of fatigue among HIV/Acquired Immune Deficiency Syndrome (AIDS) adults to gain regional insight into this disabling symptom.

Method: An institutional-based cross-sectional study was conducted among 392 HIV/AIDS patients attending an antiretroviral therapy clinic at the University of Gondar Hospital, Ethiopia using a systematic random sampling technique. Data were collected using a structured questionnaire, nine-item version Fatigue Severity Scale (FSS), and PHQ-9 (Patients Health Questionnaire 9). Logistic regression model was used to identify factors associated with the reported presence of fatigue.

Result: The mean age of the participants was $40.5 \pm 8.5$ years. The prevalence of HIV-related fatigue was $53.3 \%$ and about $66 \%$ of HIV-infected women experienced fatigue. The factors associated with fatigue experience were; female gender (AOR: $0.196,95 \% \mathrm{Cl} ; 0.05,0.92$ ), being married (AOR: $0.13,95 \% \mathrm{Cl} 0.23$, 0.7), low income (AOR: $12.3,95 \% \mathrm{Cl} 2.5,60.15)$, unemployed (AOR: $3.9,95 \% \mathrm{Cl}(1.02,14.739)$, parity (AOR: 7.99, 95\% Cl 1.66, 38.41), being anemia (AOR: 13.34, 95\% Cl 2.74, 65.01), mild weight loss (AOR: $4.995 \%$ $\mathrm{Cl} 4.33,19.5$ ) and moderate weight loss (AOR: $5.595 \% \mathrm{Cl} 3.11,21.3$ ), respectively.

Conclusion: The findings of this study revealed that experiencing fatigue is quite high among adults living with HIV. It is important for health care professionals and people living with HIV to understand; the possible causes of fatigue, remedies, and ways to reclaim energy. The predisposing factors and complications that cause fatigue should be aggressively diagnosed and treated by the clinicians.

\section{Background}

Globally by the end of 2018, about 37.9 million people were reported to live with HIV and the highestburden of it is carried by Sub-Saharan Africa (SSA) with an estimated $71 \%$ of the global tally [1]. SSA remains a hotspot of the pandemic and one in every 25 adults living with HIV. In Ethiopia, by 2018, an estimated 722248 adults live with HIV, the distribution is skewed, and the high cluster of them observed in the urban areas. The prevalence of HIV /AIDS in urban areas of the Amhara regional state was $4 \%$ in 2017 and the study area (North Gondar Zone) is a hotspot cluster, which is mapped as a geospatial prioritized zone, and the HAPCO, Ethiopia in 2019 reported that the reduction in HIV/AIDS mortality and morbidity being challenged by complacency [2-5].

Fatigue is a perceived phenomenon and often self-reported, which is defined as a subjective sensation of weariness, increased sense of effort, effort-performance mismatch, or exhaustion [6]. "Fatigue doesn't kill but it is a common, very disabling and debilitating symptom" $[7,8]$. Fatigue is one of the common disabling symptoms among many chronic diseases including HIV infection $[9,10]$. Highly active antiretroviral therapy (HAART) introduction has faded the HIV-related mortality. [11,12]. Nonetheless, the chronicity of HIV infection post-HAART era and side effects has imposed an additional burden of HIV- 
related symptoms. Several studies report an estimated prevalence of fatigue ranging from 33 to $88 \%$ $[8,13-15]$ and the symptom is highest reported among the other entire HIV-related and ART-related symptoms in HIV positive patients [16].

A previous study from a different region in Ethiopia reported the prevalence of fatigue among HIV/AIDS adults to be $51.7 \%$ [17]. The prevalence of fatigue among HIV/AIDS patients and predictors vary widely across countries and regions in the country. Several studies have reported that fatigue can negatively impact the patient's activities of daily living, quality of life, sociability, job desire, productivity, level of physical activity, psychological wellbeing, health-seeking behavior, and adherence to the HAART regimen $[15,16,18-22]$. The cause of fatigue in HIV-infected patients is probably multifactorial. Most of the studies focused on the physiological and/or psychological factors [21,23,24]. Further, evidence suggests that fatigue is associated with age, gender, malnutrition, insomnia, unemployment, poor income, family burden, depression, social support system, several disease-related factors such as the stage of the disease, anemia, the use of ART and certain laboratory parameters, as well as with socio-demographic and psychological factors $[8,9,13,14]$.

The attention in HIV care is shifting towards symptom control and improving the quality of life of HIV infected patients elsewhere [25]. Sub-Saharan Africa is the hotspot of the HIV/AIDS pandemic and a large number of people living with HIV/AIDS reside in Ethiopia [1,2]. Yet, there is a dearth of research in Ethiopia focusing on HIV-related fatigue as a primary outcome of interest and the study area is a challenging geographical terrain where fatigue can be very disabling. The objective of this study was to determine the prevalence of fatigue defined by the Fatigue Severity Scale (FSS) and the factors associated among adults living with HIV/AIDS attending antiretroviral therapy at public health facility of Gondar city, Amhara, Northwest Ethiopia.

\section{Methods}

\section{Study design, setting, and population}

An institutional-based cross-sectional design study was conducted from March to May 2019 at the antiretroviral therapy (ART) clinic, University of Gondar Specialized comprehensive hospital (UOGSCH). The hospital is found in Gondar town at $748 \mathrm{~km}$ far from Addis Ababa, a capital city of Ethiopia, to the northwest, at an altitude of 2,706 meters above sea level. UOGSCH is a 550 bedded multidisciplinary specialized governmental teaching hospital. Presently, it provides health care services to more than 5 million urban and rural inhabitants in its catchment area $(19,20)$. The HIV care unit and ART clinic started in 2003. As of 2018, this institution has served about 11277 HIV infected patients, on average 90 to 130 patients every working day. This hospital provides cost-free HIV testing, CD4 count monitoring regularly, medical consultations, counseling, and ART medications. Ethical approval was obtained from the College of Medicine and Health Sciences, ethical review committee, University of Gondar. Each participant signed written consent before participation. Adult HIV positive out-patients diagnosed by infectious disease physicians, both genders aged 18 and above, conscious and able to speak Amharic (local language) 
attending UOGSCH, ART clinic were eligible for inclusion. Pregnant and hospitalized HIV-positive patients were excluded from participation.

\section{Sampling and data collection}

The sample required for this study was determined using a single population proportion formula by assuming the prevalence of fatigue among HIV infected adults to be $50 \%$, with a $95 \%$ confidence interval, and marginal error $5 \%$. The derived power calculated sample was $n=371$. Accordingly, the final sample size with added $10 \%$ contingency was found to be 408 . From the registered list of HIV infected patients attending the HIV care/ART clinic each day during the study period, $\mathrm{K}^{\text {th }}$ patient was selected and the $1^{\text {st }}$ participant between 1 and $\mathrm{K}^{\text {th }}$ was randomly selected, then taking every $\mathrm{K}^{\text {th }}$ number thereafter. Data were collected by two trained physiotherapists who were randomly recruited from the registered list and were paid per diem. Interview method, measurements, and a structured questionnaire were used for data collection. Socio-demographic and clinical information (comorbid, duration of illness, stage, CD4 count, viral loads, prophylaxis history, hematological values) were extracted from the patients' medical records, ART logbook, and follow up cards. Fatigue Severity Scale for measuring fatigue, Patient's questionnaire-9 for measuring depression, and Insomnia severity scale were also used.

\section{Variable definitions}

Fatigue is defined using the 9-item Fatigue severity scale (FSS) [28]. Each item in FSS is scored on a 7point Likert scale ranging from 1 ("strongly disagree") to 7 (strongly agree) on how much fatigue affects the activities and lifestyle of a person [29,30]. The minimum score is " 1 " and the maximum score being " 63 ", another way of scoring is by calculating the mean of all the scores with " 1 " and " 7 " being minimum and maximum scores respectively. A cut-off score of 4 or more was considered indicative of problematic fatigue [29]. A patient was considered physically active if the participant reported activity $\geq 150$ min per week [31]. The Patient Health Questionnaire-9 (PHQ-9) was used to measure the depression level (case cut off $\geq 5$ ) of the participants [32]. A participant who scored $>7$ on the Insomnia Severity Scale was defined as an insomnia case. Anemia was defined according to WHO criteria. For men, anemia was defined as hemoglobin concentration $(\mathrm{Hb})$ less than $13 \mathrm{~g} / \mathrm{dl}$, while for women; the cut-off is less than 12 $\mathrm{g} / \mathrm{dl}$ [33]. HIV infected patients with weight loss or wasting were recognized using a set of rules/criteria developed by the expert physicians in the HIV care clinic, UOGH, and investigators of this study (Additional file 1).

\section{Statistics}

Data were coded and entered into EPI Info version 7.0 and exported to IBM Statistical Package for Social Sciences (SPSS) version 24 for Windows. The representativeness of the study sample to the research setting population during the study period was examined using formulas proposed by Cochrane to calculate the normal approximation frequency [34]. Descriptive statistics were used for all participant characteristics and factors associated with fatigue defined by FSS. Co-linearity diagnostics were performed for each of the variables in the full model. All variance inflation factors were $<10$, and the 
condition inflation factors were $<30$, indicating that multi-colinearity was not a problem for this model. With fatigue (categorized: yes versus no) as the dependent variable, univariate and multivariate binary logistic regression analyses were carried out to examine the association with different independent variables. Variables were entered into the model using forced entry and categories were used as covariates for detailed analyses. Model fit was assessed by the described method [35] and results were considered statistically significant when $95 \%$ confidence intervals not containing unity (equal to $p$-value < 0.05). Chi-square test or Fisher's exact test was used to determine the prevalence distribution of fatigue and estimate its association with different predictor variables. Predictor variables that were found to be associated with HIV-related fatigue (categorized; yes or no) in univariate model were gender, marital status, income, educational status, occupation, having children, anemia, weight loss, total duration since HIV confirmed, co-morbid condition, WHO classification clinical stage of HIV/AIDS and CD4 counts and the same were included in multivariate analysis. Interaction terms were used to examine the potential association between predictor variables and fatigue. When a clear sub-group seemed present in the data set, significance testing (Pearson $X^{2}$ ) and, if appropriately sized subgroups per category remained, the same was exported to the logistic model. This study is reported in accordance with the STROBE reporting guidelines (Additional file 2).

\section{Results}

\section{Socio-demographic characteristics}

A total of 408 HIV positive adults were approached for consent, among which 392 participants consented to participate in this study, with a response rate of $96.1 \%$ and this is more than $100 \%$ of the power calculated sample size $(n=371)$. Those 16 patients who did not consent or agree to participate in the study reasoned lack of interest and time constrain.

The mean age of the participants was $40.5( \pm 8.5)$ years and the majority of them $259(66.1 \%)$ were females. Only $7.9 \%$ of them reported to be from rural, majority of the participants were underweight (52.8\%), above one-fourth did not have formal education. About $47 \%$ reported to be jobless and $43 \%$ answered to have low income (< 1500 Ethiopian birr). The majority of the participants $77.3 \%$ reported lack of family support. Most of the subjects ( $94.1 \%$ and $86.9 \%)$ self-reported no previous or current smoking and alcohol habits respectively Table 1.

Table 1 Socio-demographic characteristics of people living with HIV/AIDS attending ART clinic, in the University of Gondar Hospital, University of Gondar, Northwest Ethiopia, 2019 (n=392). 


\begin{tabular}{|c|c|c|c|c|c|}
\hline \multirow[t]{2}{*}{ Variables } & \multirow{2}{*}{$\begin{array}{c}\text { Sample total } \\
\text { n (\%) }\end{array}$} & \multicolumn{2}{|c|}{ Fatigue n (\%) } & \multirow[t]{2}{*}{$x^{2}$} & \multirow[t]{2}{*}{$P$} \\
\hline & & Yes & No & & \\
\hline \multicolumn{6}{|l|}{ Sex } \\
\hline Female & $259(66.1)$ & $173(66.8)$ & $86(33.2)$ & 55.7 & 0.000 \\
\hline Male & $133(33.9)$ & $36(27.1)$ & $97(72.9)$ & & \\
\hline \multicolumn{6}{|l|}{ Age group (years) } \\
\hline$<25$ & $16(41)$ & $04(25)$ & $12(75)$ & 5.7 & 0.06 \\
\hline $25-44$ & $255(65.1)$ & $141(55.3)$ & $114(44.7)$ & & \\
\hline$\geq 45$ & $121(30.9)$ & $64(52.9)$ & $57(47.1)$ & & \\
\hline \multicolumn{6}{|l|}{ Religion } \\
\hline Orthodox & $310(79.1)$ & $164(52.9)$ & $146(47.1)$ & 0.19 & 0.91 \\
\hline Muslim & $48(12.2)$ & $18(52.8)$ & $16(47.2)$ & & \\
\hline Protestant & $34(8.7)$ & $27(56.2)$ & $21(43.8)$ & & \\
\hline \multicolumn{6}{|l|}{ Marital status } \\
\hline Single & $91(23.2)$ & $44(48.4)$ & $47(51.6)$ & 18.3 & 0.04 \\
\hline Married & $203(51.8)$ & $112(55.2)$ & $91(44.8)$ & & \\
\hline Divorced & $75(19.1)$ & $35(46.7)$ & $40(53.3)$ & & \\
\hline Widowed & $23(5.9)$ & $18(78.3)$ & $05(21.7)$ & & \\
\hline \multicolumn{6}{|l|}{ Level of education } \\
\hline No formal schooling & $114(29.1)$ & $68(59.6)$ & $46(40.4)$ & 7.1 & 0.044 \\
\hline Grade 1-6 & $82(20.9)$ & $38(46.3)$ & $44(53.7)$ & & \\
\hline Grade 7-8 & $53(13.5)$ & $30(56.6)$ & $23(43.4)$ & & \\
\hline Grade 9-10 & $53(13.5)$ & $32(60.4)$ & $21(39.6)$ & & \\
\hline Grade 11-12 & $44(11.2)$ & $19(43.2)$ & $25(56.8)$ & & \\
\hline Diploma and above & $46(11.7)$ & $22(47.8)$ & $24(52.2)$ & & \\
\hline \multicolumn{6}{|l|}{ Residence } \\
\hline Urban & $361(92.1)$ & $197(54.6)$ & $164(45.4)$ & 2.88 & 0.81 \\
\hline Rural & $31(7.9)$ & $12(38.7)$ & $19(61.3)$ & & \\
\hline \multicolumn{6}{|l|}{ BMI $\left(\mathrm{kg} / \mathrm{m}^{2}\right)$} \\
\hline Underweight $(<18.5)$ & $207(52.8)$ & $26(12.6)$ & $181(87.4)$ & 292.1 & 0.000 \\
\hline Normal weight (18.5-24.9) & $172(43.9)$ & $170(98.8)$ & $02(1.2)$ & & \\
\hline Overweight (25-29.9) & $10(2.6)$ & $09(90)$ & $01(10)$ & & \\
\hline Obese $(>29.9)$ & $03(0.7)$ & $02(66.7)$ & $01(33.3)$ & & \\
\hline \multicolumn{6}{|l|}{ Employment status } \\
\hline Unemployed & $186(47.4)$ & $157(84.4)$ & $29(15.6)$ & 137.4 & 0.000 \\
\hline Employed & $206(52.6)$ & $52(25.2)$ & $154(74.8)$ & & \\
\hline \multicolumn{6}{|l|}{ Income/wealth index } \\
\hline Low income & $170(43.4)$ & $147(86.5)$ & $23(13.5)$ & 202.5 & 0.000 \\
\hline Medium income & $91(23.2)$ & $56(61.5)$ & $35(38.5)$ & & \\
\hline High income & $131(33.4)$ & $06(4.6)$ & $125(95.4)$ & & \\
\hline \multicolumn{6}{|l|}{ Having children } \\
\hline Yes & $243(62.0)$ & $182(74.9)$ & $61(25.1)$ & 119.6 & 0.000 \\
\hline No & $149(38.0)$ & $27(18.1)$ & $122(81.9)$ & & \\
\hline \multicolumn{6}{|l|}{ Family support } \\
\hline Yes & $89(22.7)$ & $38(42.7)$ & $51(57.3)$ & 4.3 & 0.91 \\
\hline No & $303(77.3)$ & $171(56.4)$ & $132(43.6)$ & 6.2 & 0.4 \\
\hline \multicolumn{6}{|l|}{ Smoking } \\
\hline Current smokers & $16(4.1)$ & $11(68.7)$ & $5(31.3)$ & 7.8 & 0.2 \\
\hline
\end{tabular}




\begin{tabular}{|l|l|l|l|l|l|} 
Previous smoker & $07(1.8)$ & $4(57.1)$ & $3(42.9)$ & & \\
\hline Never smoked & $369(94.1)$ & $194(52.6)$ & $175(47.4)$ & & \\
\hline Alcohol & & & & & \\
\hline Never & $341(86.9)$ & $175(51.3)$ & $166(48.7)$ & 5.4 & 0.34 \\
\hline Current & $46(11.8)$ & $31(67.4)$ & $15(32.6)$ & & \\
\hline Past & $05(1.3)$ & $03(60)$ & $02(40)$ & & \\
\hline
\end{tabular}

\section{Clinical characteristics}

Among the total participants, $94.6 \%$ were on ART during the study period. About $40 \%$ of the participants had been diagnosed with HIV infection for $>60$ months as of May 2019. The recent CD 4 cell count of two hundred and fifty-one $(n=251,64 \%)$ participants was below $350 \mathrm{cell} / \mathrm{mm}^{3}$, and about $3 / 4^{\text {th }}$ of the participants were diagnosed to be in clinical stage I and II. Majority of participants (93\%) were diagnosed with weight loss, nearly half of them (48.7\%) had anemia, and only $4.6 \%$ and $9.4 \%$ had been diagnosed to have diabetes mellitus and hypertension respectively. According to the PHQ-9 score of depression, about $3 / 4^{\text {th }}$ of the HIV-infected adult participants were suffering from depression, of those, almost half of them had severe depression. About one in four reported to suffer insomnia $23.2 \%$ and $29.8 \%$ were physically active Table 2.

Table 2 Clinical characteristics of people living with HIV/AIDS attending ART clinic at University of Gondar Hospital, University of Gondar, Northwest Ethiopia, 2019 (n=392). 


\begin{tabular}{|c|c|c|c|c|c|}
\hline \multirow[t]{2}{*}{ Variables } & \multirow{2}{*}{$\begin{array}{c}\text { Sample total } \\
\text { n (\%) }\end{array}$} & \multicolumn{2}{|c|}{ Fatigue $\mathrm{n}(\%)$} & \multirow[t]{2}{*}{$x^{2}$} & \multirow[t]{2}{*}{$\mathrm{P}$} \\
\hline & & Yes & No & & \\
\hline \multicolumn{6}{|l|}{ Type of HAART regimen } \\
\hline $\mathrm{AZT}+3 \mathrm{TC}+\mathrm{NVP}$ & 155 (39.5) & $74(47.7)$ & $81(52.3)$ & 1.3 & 0.7 \\
\hline $\mathrm{AZT}+3 \mathrm{TC}+\mathrm{EFV}$ & $16(4.1)$ & $7(43.8)$ & $9(56.2)$ & & \\
\hline $\mathrm{TDF}+3 \mathrm{TC}+\mathrm{EFV}$ & $118(30.1)$ & $76(64.4)$ & 62 (35.6) & & \\
\hline $\mathrm{TDF}+3 \mathrm{TC}+\mathrm{NVP}$ & $63(16.1)$ & $27(42.9)$ & 36 (57.1) & & \\
\hline $\mathrm{ABC}+\mathrm{DDI}+\mathrm{LPV} / \mathrm{R}$ & $19(4.8)$ & $14(73.7)$ & 05 (26.3) & & \\
\hline Pre-HAART & $21(5.4)$ & $11(52.4)$ & $10(47.6)$ & & \\
\hline \multicolumn{6}{|l|}{ CD4 counts } \\
\hline$<200$ cells $/ \mathrm{mm} 3$ & $23(5.8)$ & $07(30.4)$ & 16 (69.6) & 4.5 & 0.23 \\
\hline $200-350$ cells $/ \mathrm{mm} 3$ & $228(58.2)$ & $128(56.1)$ & $100(43.9)$ & & \\
\hline$>350$ cells $/ \mathrm{mm} 3$ & $141(36.0)$ & $73(51.8)$ & $68(48.2)$ & & \\
\hline \multicolumn{6}{|l|}{ Duration of HIV infection } \\
\hline$<60$ months & $232(59.2)$ & $176(75.9)$ & $56(24.1)$ & 119.7 & 0.000 \\
\hline $60-100$ months & $87(22.2)$ & $24(27.6)$ & $63(72.4)$ & & \\
\hline$>100$ months & 73 (18.6) & 09 (12.3) & 64 (87.7) & & \\
\hline \multicolumn{6}{|c|}{\begin{tabular}{l|l} 
WHO HIV/AIDS clinical stage & \\
\end{tabular}} \\
\hline Stage I & $230(58.7)$ & $99(43)$ & $131(57)$ & 25.1 & 0.00 \\
\hline Stage II & $80(20.4)$ & $51(63.8)$ & 29 (36.2) & & \\
\hline Stage III & $81(20.7)$ & $58(71.6)$ & $23(28.4)$ & & \\
\hline Stage IV & $1(0.3)$ & $01(100)$ & $0(0)$ & & \\
\hline \multicolumn{6}{|l|}{ Weight loss } \\
\hline No weight loss & $26(6.6)$ & $24(92.3)$ & $02(7.7)$ & 31.9 & 0.01 \\
\hline Mild weight loss & $148(37.8)$ & $102(68.9)$ & 46 (31.1) & & \\
\hline Moderate weight loss & $122(31.1)$ & $63(51.6)$ & 59 (48.4) & & \\
\hline Severe weight loss & $96(24.5)$ & $20(20.8)$ & $76(79.2)$ & & \\
\hline \multicolumn{6}{|l|}{ Anemic } \\
\hline Yes & $191(48.7)$ & $180(94.2)$ & $11(5.8)$ & 111.2 & 0.000 \\
\hline No & $201(51.3)$ & 29 (14.4) & $172(85.6)$ & & \\
\hline \multicolumn{6}{|l|}{ Diabetes mellitus } \\
\hline Yes & $18(4.6)$ & $15(83.3)$ & $03(16.7)$ & 13.6 & 0.001 \\
\hline No & $374(95.4)$ & $194(51.9)$ & $180(48.1)$ & & \\
\hline \multicolumn{6}{|l|}{ Hypertension } \\
\hline Yes & $11(9.4)$ & $10(90.8)$ & $01(9.1)$ & 9.2 & 0.002 \\
\hline No & $381(89.6)$ & $198(52)$ & $183(48)$ & & \\
\hline \multicolumn{6}{|l|}{ Other co-morbid conditions } \\
\hline Yes & $37(9.4)$ & $23(62.2)$ & $14(37.8)$ & 15.3 & 0.000 \\
\hline No & $355(90.6)$ & $186(52.4)$ & $169(47.6)$ & & \\
\hline \multicolumn{6}{|l|}{ Depression } \\
\hline Yes & 283 & $204(72.1)$ & 79 (27.9) & 144.8 & 0.000 \\
\hline No & $109(28.1)$ & $21(19.3)$ & $88(80.7)$ & & \\
\hline \multicolumn{6}{|l|}{ Insomnia } \\
\hline Yes & $91(23.2)$ & $43(47.3)$ & $48(52.7)$ & 1.66 & 0.68 \\
\hline No & $30(76.8)$ & $166(55.1)$ & $135(44.9)$ & & \\
\hline \multicolumn{6}{|l|}{ Physical activity } \\
\hline Yes & $117(29.8)$ & $41(35.1)$ & $76(64.9)$ & 5.49 & 0.014 \\
\hline No & $275(70.2)$ & $178(64.7)$ & 97 (35.3) & & \\
\hline
\end{tabular}




\begin{tabular}{|l|l|l|l|l|l|} 
Physical disability & & & & \\
\hline Yes & $12(3.1)$ & $10(83.3)$ & $02(16.7)$ & 2.48 & 0.59 \\
\hline No & $380(96.9)$ & $199(52.4)$ & $181(47.8)$ & & \\
\hline
\end{tabular}

\section{Fatigue among adults HIV/AIDS and distribution}

Among 392 participants, two hundred and nine ( $\mathrm{n}=209,53.3 \% ; 95 \% \mathrm{Cl} ; 48.5,58.5)$ were found to have the experience of fatigue. A statistically significant difference was observed in the prevalence of fatigue between genders (men 27.1 versus women $66.8 \% ; \chi^{2}(1, n=392)=55.7, p<0.0001$, phi $\left.=0.37\right)$. The majority of widowed participants reported fatigue $78.3 \%$ followed by married $55 \%$ and single $48 \%$. The experience of fatigue was higher among anemic participants 180 (94.2\%), unemployed 157 (84.4\%), and those who reported low income 147 (86.5\%). Depression was significantly associated with experience of fatigue (depression 72.1\% versus no depression $27.9 \% ; \chi^{2}(1, n=392)=144.8, p<0.0001$, phi $=0.61$ ). The frequency distribution of fatigue symptoms for the 9 -item fatigue severity scale (FSS) reported by the respondents was almost even and majority of them reported that "exercise brings on my fatigue" $57.4 \%$ (225/392), and "I am easily fatigued" 55.9\% (219/392) Figure 1.

\section{Regression analysis}

Prior to analysis, fourteen variables potentially related to the experience of fatigue were identified for regression analysis: gender, age, marital status, education level, employment status, income index, parity, duration of HIV, HIV/AIDS clinical-stage, weight loss, anemia, comorbid conditions, depression, and physical activity. Of those, age, duration of HIV, and physical activity were found not significantly associated in univariate analyses. The remaining eleven variables were entered into the multivariate model. In multivariate analyses when adjusted for other independent variables; gender, marital status, income level, employment status, parity, anemia, depression, and weight loss were found to be significant predictors.

HIV-infected adult women patients were 3 times more likely to experience fatigue than their counterparts [AOR 3.19, $955 \mathrm{Cl}: 1.05,6.92$ ], patients who were married and living with their spouse were $87 \%$ less likely to experience fatigue than those who were not with their spouse. Those who were unemployed and had low income were four times (AOR 3.9, 95\% Cl: 1.02, 14.74) and twelve times (AOR 12.3, 95\% Cl: 2.5, 60.15) more likely to suffer from fatigue. HIV-infected patient those who have children were 7.9 times more likely to have fatigue compared to those who did not have children (AOR 7.99, 95\% Cl: 1.66, 38.41). HIV/AIDS patients diagnosed with anemia and depression were 13 times (AOR 13.34, 95\% Cl: 2.74, 65.01) and 4 times (AOR $4.01 .95 \% \mathrm{Cl}: 1.10,15.6)$ respectively. Those who had mild and moderate weight loss were about five times more likely to develop fatigue as compared to those with no weight loss ( AOR 4.9, $95 \% \mathrm{Cl}: 4.33,19.51)$ and (AOR $5.5,95 \% \mathrm{Cl}: 3.11,21.37)$ respectively Table 3 . The interaction effect of unemployment, low income, gender, having children, and depression was not significantly associated with fatigue. 
Table 3 Univariate and multivariate analysis for the associated and predicting socio-demographic and clinical characteristics to HIV-related fatigue, 2019 (n=392), Ethiopia. 


\begin{tabular}{|c|c|c|c|c|}
\hline \multirow[t]{2}{*}{ Variables } & \multicolumn{2}{|c|}{ Fatigue } & \multirow{2}{*}{$\begin{array}{l}\text { Univariate } \\
\text { COR }(95 \% \mathrm{CI})\end{array}$} & \multirow{2}{*}{$\begin{array}{l}\text { Multivariate } \\
\text { AOR }(95 \% \mathrm{CI})\end{array}$} \\
\hline & Yes & No & & \\
\hline \multicolumn{5}{|l|}{ Sex } \\
\hline Women & 173 & 86 & $5.42(3.45,8.6) *$ & $3.196(1.05,6.92) *$ \\
\hline Men & 36 & 97 & 1 (ref) & 1 (ref) \\
\hline \multicolumn{5}{|l|}{ Marital status } \\
\hline Single & 44 & 47 & 1 (ref) & 1 (ref) \\
\hline Married & 112 & 91 & $1.32(0.80,2.16)^{*}$ & $0.13(0.23,0.7)^{*}$ \\
\hline Divorced & 35 & 40 & $0.94(0.51,1.72)^{*}$ & $0.17(0.03,1.2)$ \\
\hline Widowed & 18 & 5 & $3.85(1.32,11.24)^{*}$ & $0.53(0.01,2.3)$ \\
\hline \multicolumn{5}{|l|}{ Income } \\
\hline Low income & 147 & 23 & $133.15(52.56,337.3) *$ & $12.3(2.5,60.15) *$ \\
\hline Medium income & 56 & 35 & $33.33(13.26, \quad 83.78)$ & $7.05(1.49,33.49)$ \\
\hline High income & 6 & 125 & 1 (ref) & 1 (ref) \\
\hline \multicolumn{5}{|l|}{ Educational status } \\
\hline Illiterate & 68 & 46 & $1.6(0.81,3.21) *$ & $0.422 \quad(0.07,2.63)$ \\
\hline Grade 1-6 & 38 & 44 & $0.94(0.46,1.94)$ & $0.184(0.026,1.29)$ \\
\hline Grade 7-8 & 30 & 23 & $1.42(0.64,3.15)$ & $0.12(0.008,1.63)$ \\
\hline Grade 9-10 & 32 & 21 & $1.66(0.75,3.7)$ & $0.122(0.012,1.25)$ \\
\hline Grade 11-12 & 19 & 25 & $0.83(0.36,1.9)$ & $0.55(0.06,4.1)$ \\
\hline Diploma and above & 22 & 24 & 1 (ref) & 1 (ref) \\
\hline \multicolumn{5}{|l|}{ Occupation status } \\
\hline Employed & 52 & 154 & 1 (ref) & 1 (ref) \\
\hline Unemployed & 157 & 29 & $16.033(9.67,26.59)^{*}$ & $3.9(1.02,14.74) *$ \\
\hline \multicolumn{5}{|l|}{ Having children } \\
\hline Yes & 182 & 61 & 13.48( 8.11,22.40)* & $7.99(1.66,38.41)^{*}$ \\
\hline No & 27 & 122 & 1 (ref) & 1 (ref) \\
\hline \multicolumn{5}{|l|}{ Anemia } \\
\hline Yes & 180 & 11 & $17.05(7.01$ & $13.34(2.74,65.01) *$ \\
\hline No & 29 & 172 & 1 (ref) & 1 (ref) \\
\hline \multicolumn{5}{|l|}{ Depression } \\
\hline Yes & 204 & 79 & $5.61(2.03,19.1)^{*}$ & $4.01(1.10,15.64)^{*}$ \\
\hline No & 21 & 88 & $1 \mathrm{ref}$ & 1 ref \\
\hline \multicolumn{5}{|l|}{ Weight loss } \\
\hline No weight loss & 6 & 20 & 1 (ref) & 1 (ref) \\
\hline Mild weight loss & 109 & 39 & $12.3(3.24,24.22)^{*}$ & $4.9(4.33,19.51) *$ \\
\hline Moderate weight loss & 99 & 23 & $13.9(2.89,27.5) *$ & $5.5(3.11,21.37) *$ \\
\hline Severe weight loss & 45 & 51 & $7.8(1.01,15.2)^{*}$ & $2.91(1.12,9.74)$ \\
\hline \multicolumn{5}{|l|}{ Duration of HIV } \\
\hline$<60$ & 176 & 56 & $22.35(10.65,47.78)$ & $0.762(0.153,3.79)$ \\
\hline $60-100$ & 24 & 63 & $2.71(1.17,6.28)$ & $1.93(0.392,9.45)$ \\
\hline$\geq 100$ & 9 & 64 & 1 (ref) & 1 (ref) \\
\hline \multicolumn{5}{|l|}{ Co-morbid condition } \\
\hline Yes & 37 & 9 & $4.16(1.95,8.88)^{*}$ & $4.31(0.93,20.05)$ \\
\hline No & 172 & 174 & 1 (ref) & 1 (ref) \\
\hline \multicolumn{5}{|l|}{ Clinical stage of HIV } \\
\hline Stage 1 & 99 & 131 & 1 (ref) & 1 (ref) \\
\hline Stage 2 & 51 & 29 & $2.33(1.38,3.94)$ & $0.34(0.04,2.79)$ \\
\hline Stage 3 and 4 & 59 & 23 & $3.39(1.1,5.9)$ & $4.99(0.67,37.24)$ \\
\hline CD4 counts & & & & \\
\hline
\end{tabular}




\begin{tabular}{|l|l|l|l|l|}
$<200$ cells $/ \mathrm{mm} 3$ & 6 & 17 & $0.254(0.12,0.54)$ & $1.28(0.23,7.14)$ \\
\hline $200-350$ cells $/ \mathrm{mm} 3$ & 126 & 102 & $1.14(0.74,1.76)$ & $0.884(0.254,3.08)$ \\
\hline$>350$ cells $/ \mathrm{mm} 3$ & 77 & 64 & $1(\mathrm{ref})$ & $1 .($ ref $)$ \\
& & & & \\
\hline
\end{tabular}

*Denotes significant association of the characteristics with HIV-related fatigue in the multivariate model, AORAdjusted odd ratio, CI - Confidence Interval

\section{Discussion}

The findings of this study showed that the overall prevalence of fatigue using the 9-item Fatigue Severity Scale (FSS) among HIV/AIDS patients attending the ART clinic at University of Gondar specialized comprehensive hospital in Gondar city, Ethiopia was 53.3\% (95\% Cl: 48.5, 58.4). This is to some extent at the higher end of the prevalence range (33 to 88\%) reported previously in the literature $[8,13-15]$. This finding is harmonized with the regional study conducted in Tigray, Ethiopia 51.7\%, studies in USA 54\%, South Africa 55\%, and Canada 54\% [17,29,36,37]. Larger sample size, similar patient characteristics, and inclusion criteria in these studies could explain the consistent findings.

Surprisingly, in this study, there is no association between advanced HIV disease marked by CD4 count, duration of HIV, ART regimen, clinical stage of HIV, and the experience of fatigue when adjusted for the other independent variables in the regression model. Although drugs like dovudine and didanosine are frequently reported to have fatigue as side effects. Antiretroviral agents might help the control of viral replication and slower disease progression, which could mitigate the risk of fatigue associated with ART. Further, the distinct difference between the perception of fatigue and performance fatigue, level of fatigue, and energy demand of the respondents could have influenced the findings [38]. Then again, the finding of this result was lower than the findings reported in other studies done in a rural district in Southwest Uganda 61\% [39], South Africa 66.7\% [40], Rochester, USA 64\% [41], China 86.8\% [42], and the United Kingdom 65.1\% [43]. This discrepancy might be due to the reasons that the Ugandan and the USA included lesser samples 212 and 128 respectively. Moreover, the Ugandan study used Memorial Symptom Assessment Scale-Short Form (MSAS-SF), the UK used a self-administered questionnaire with Chalder Fatigue Scale to measure fatigue, though the study from USA used similar outcome measure (FSS) the cutoff was lower, the study in South Africa used convenient sampling to report multiple selfreported symptoms with fatigue one among those. The Chinese study was based secondary source data (case-report form) using a retrospective design. Overall, the variations in the sampling method, study design, outcome tools, data collection method, and clinical characteristics of the patients could explain these discrepancies.

In this study, the key predictors that were significantly associated with fatigue among HIV/AIDS adults were clinically diagnosed anemia, low income, parity, and living without a spouse. Likewise, studies done in the USA and China reported an association between fatigue and anemia $[42,44,45]$. Fatigue is the cardinal symptom of anemia, a prognostic marker of disease progression, and frequently reported as a predictor of morbidity and mortality among HIV/AIDS patients. The negative effects of HIV infection and 
CART on the hematopoiesis contribute to low hemoglobin concentration leading to impaired oxygen transport to the vital organs and musculoskeletal system resulting in fatigue. The resolution of HIVrelated anemia has been shown to improve fatigue individuals with HIV [46].

We are unsurprised that depression is significantly associated with fatigue, low energy or tiredness itself is a depressive symptom. Similar to this study, many studies and a systematic review of 42 studies reported that inadequate income, unemployment, and depression are stronger predictors and uniformly associated with HIV related fatigue [36,47-49]. Less energy, lack of work capacity, an inclination to work and reduced motivation may eventually result in unemployment and inadequate income. Importantly, fatigue that precedes depression or results from depression is a distinct health outcome among HIV/AIDS patients and the interaction can sometimes become a vicious cycle. The present study also found that female patients were more likely to perceive fatigue than men. This finding is similar to the studies conducted in South Africa [50], Canada [51], and a systematic review [49]. The mean age of women in this was lower than men, majority of those who diagnosed with anemia and weight loss were women. Besides, a higher representation of women in this study could have favored this association.

In this study, having children was associated with the experience of fatigue. A similar association was reported by studies in the USA, France, and South Africa [36,48,52]. The findings might be attributed to additional responsibility and workload in terms of the physical, social, and financial burden that are associated with having children. However, participants who were married and living with their spouse was a protective factor for fatigue than those who lived without a spouse. Emotional stress, grief, loneliness, and depression attributed to the loss of spouse, separation, and lack of support could be the possible explanation for likely risk of fatigue among those living alone.

The current study also found the mild and moderate weight loss was significantly associated with fatigue. This was similar to the study done in Western Cape, Bellville, South Africa [53], and Southwest Uganda [39]. Although the association between fatigue and severe weight loss is non-significant, the coefficient above 1 in the regression model explains the risk of fatigue. Malnourishment, wasting, loss of appetite, side-effects of drugs, illness related to co-infections, and HIV related complications are blamed for unexplained weight loss among HIV/AIDS patients. Each of these factors can cause loss of energy and/or tiredness and are predictor or risk factor for developing fatigue.

Limitations of this study include, unlike longitudinal design, which explains the temporal relationship, the cross-sectional nature of the data reported in this study might reduce generalizability. We were not able to distinguish the role of the HAART regiment due to the limited enrolment of pre-ART patients. Further, we could not draw any conclusions related to the direction of causality, and cause of fatigue. However, as a description of HIV-infected adult patients in Ethiopia in clinical practice, we believe our power calculated sample size, representative sample of clinical population and use of a valid outcome tool should enhance the external validity of the data presented and provide a powered preliminary insight of the burden and factors related to HIV-related fatigue in Ethiopia. Future studies should explore the effect of fatigue on 
the adherence to ART regimen, disease status, and other relevant clinical outcomes among adults with HIV/AIDS in Ethiopia.

\section{Conclusion}

The prevalence of fatigue was found to be high in people living with HIV/AIDS. From all the sociodemographic factors and HIV/AIDS related medical factors that were studied, being female, being married, low income, unemployed, having children, severe weight loss, and anemia were found statistically associated with fatigue. Hence, early detection of the HIV-related fatigue and its underlying treatable causes permits patient education, controlling risk factors, and treat these conditions when they are present or predisposed.

\section{Abbreviations}

AIDS- Acquired immune deficiency syndrome, AOR- Adjusted odds ratio, ART: antiretroviral therapy, ATN: antiretroviral therapy toxic neuropathy, BMI- Body Mass Index, cART- combination Antiretroviral Therapy, Cl: Confidence Interval, COR- Crude Odd Ratio, FSS- Fatigue Severity Scale, HAART: highly active antiretroviral therapy, HAPCO- HIV/AIDS Prevention and Control Office, HIV- Human immunodeficiency virus, MSAS-SF- Memorial Symptom Assessment Scale Short Form, PHQ-9- Patients Health Questionnaire-9, UOGCSH- University of Gondar Specialized Comprehensive Hospital, USA- United States of America, WHO- World Health Organization

\section{Declarations}

\section{Ethics approval and consent to participate}

The study was conducted after obtaining ethical approval from the Institutional Review Board (IRB), CMHS, University of Gondar (Ref no; SOM/087/9/2017). Permissions were obtained from the regional public health institute and the authorities of the study site before the study. Written consent was obtained from each participant after explaining the study, its objective, benefits, and its importance. Information's were recorded anonymously and confidentiality and beneficence were assured throughout the study period.

\section{Consent to publish}

Not applicable

\section{Competing interests}

The authors declare that they have no conflict of interest.

\section{Funding}


This study was funded by the University of Gondar (Grant ref no: 08792017). The views presented in the article are the authors and not necessarily express the views of the funding organization. University of Gondar did not involve in the design of the study, data collection, analysis, and interpretation.

\section{Availability of data and materials:}

All data relevant to our findings are contained within the manuscript. Requests for further details on the dataset and queries concerning data sharing shall be arranged based on a reasonable request to the corresponding author.

\section{Authors' contributions}

MB brought the original idea and was involved in the proposal writing, designed the study, and participated in all the implementation stages of the project. MB and BJ analyzed the data and wrote the manuscript. BF, SF, SM, and MB participated in the conception of the original idea and were involved in the proposal writing, finalized the write-up of the manuscript, and critically revised the manuscript for important intellectual content. BJ, MB, SM, SF, and BF were responsible for critically revising the research proposal and the manuscript, and participated in its design and interpretation. BJ and MB were involved in the design of the work and approved the version to be published. All the authors read and approved the final version of the manuscript.

\section{Acknowledgments}

Firstly, we would like to express our deepest gratitude to the University of Gondar for ethical approval and fully funding this project. Our gratitude and appreciation go to data collectors, adults living with HIV attending HIV care clinic who participated in this study. We are also grateful to all hospital authorities and HIV care clinic staffs for their cooperation.

\section{Author's detail}

MB and BJ work in the Department of Physiotherapy, School of Medicine and Health Sciences, University of Gondar Specialized Comprehensive Hospital, University of Gondar, Gondar, Ethiopia. MBC works in the Department of Physiotherapy, School of Medicine and Health Sciences, University of Gondar Specialized Comprehensive Hospital, University of Gondar, Gondar, Ethiopia and is a Ph.D. Candidate, School of rehabilitation therapy, Queen's University, Canada.

BF works in the Department of Physiotherapy, School of Medicine, College of Health Sciences and Ayder comprehensive specialized Hospital, Mekelle University, Ethiopia

SMA works in the Department of Human Nutrition, Institute of Public Health, College of Medicine and Health Science, University of Gondar, Ethiopia

\section{References}


1. Global HIV \& AIDS statistics - 2019 fact sheet I UNAIDS [Internet]. [cited 2020 Jun 6]. Available from: https://www.unaids.org/en/resources/fact-sheet

2. HIV Prevention in Ethiopia: National Road Map (2018-2021) [Internet]. UNFPA Ethiopia. 2018 [cited 2020 Jun 6]. Available from: https://ethiopia.unfpa.org/en/publications/hiv-prevention-ethiopianational-road-map-2018-2021

3. Federal HIV/AIDS Prevention and Control Office (HAPCO), Ethiopian Strategic Plan for Intensifying Multisectoral HIV/AIDS Response 2004-2008, Addis Ababa, December 2004, 56 pp. Available from: http://www.oit.org/aids/legislation/WCMS_125381/lang--en/index.htm

4. Federal HIV/AIDS Prevention and Control Office (HAPCO) | Devex [Internet]. [cited 2020 Jun 6]. https://www.devex.com/organizations/federal-hiv-aids-prevention-and-control-office-hapco-51407

5. Kibret GD, Ferede A, Leshargie CT, Wagnew F, Ketema DB, Alebel A. Trends and spatial distributions of HIV prevalence in Ethiopia. Infectious diseases of poverty. 2019;8(1):90.

6. Kluger BM, Krupp LB, Enoka RM. Fatigue and fatigability in neurologic illnesses: proposal for a unified taxonomy. Neurology. 2013;80(4):409-16.

7. Lewis $G$, Wessely $S$. The epidemiology of fatigue: more questions than answers. Journal of epidemiology and community health. 1992;46(2):92.

8. Perazzo JD, Webel AR, Voss JG, Prince-Paul M. Fatigue symptom management in people living with human immunodeficiency virus. Journal of hospice and palliative nursing: JHPN: the official journal of the Hospice and Palliative Nurses Association. 2017;19(2):122.

9. Gallant JE. 100 Questions \& Answers about HIV and AIDS. Jones \& Bartlett Publishers; 2016.

10. Loades M, Coetzee B, Du Toit S, Kagee A. '... But i'm still tired': the experience of fatigue among South African adolescents receiving antiretroviral therapy. AIDS care. 2018;30(6):746-50.

11. Croxford S, Kitching A, Desai S, Kall M, Edelstein M, Skingsley A, et al. Mortality and causes of death in people diagnosed with HIV in the era of highly active antiretroviral therapy compared with the general population: an analysis of a national observational cohort. The Lancet Public Health. 2017;2(1):e35-46.

12. Zuniga JM, Whiteside A, Ghaziani A, Bartlett JG. A decade of HAART: the development and global impact of highly active antiretroviral therapy. Oxford University Press; 2009.

13. Jong E, Oudhoff LA, Epskamp C, Wagener MN, van Duijn M, Fischer S, et al. Predictors and treatment strategies of HIV-related fatigue in the combined antiretroviral therapy era. Aids. 2010;24(10):1387405.

14. Payne B, Hateley C, Ong E, Premchand N, Schmid M, Schwab U, et al. HIV-associated fatigue in the era of highly active antiretroviral therapy: novel biological mechanisms? HIV medicine. 2013;14(4):247-51.

15. Barroso J, Voss JG. Fatigue in HIV and AIDS: an analysis of evidence. Journal of the Association of Nurses in AIDS Care. 2013;24(1):S5-14. 
16. Barroso J, Harmon JL, Madison JL, Pence BW. Intensity, chronicity, circumstances, and consequences of HIV-related fatigue: a longitudinal study. Clinical nursing research. 2014;23(5):51428.

17. Gebreyesus T, Belay A, Berhe G, Haile G. Burden of fatigue among adults living with HIV/AIDS attending antiretroviral therapy in Ethiopia. BMC Infectious Diseases. 2020;20:1-10.

18. Barroso J, Voss JG. Fatigue in HIV and AIDS: an analysis of evidence. Journal of the Association of Nurses in AIDS Care. 2013;24(1):S5-14.

19. George Dalmida S, McDonnell Holstad M, Fox R, Mara Delaney A. Depressive symptoms and fatigue as mediators of relationship between poor sleep factors and medication adherence in HIV-positive women. Journal of Research in Nursing. 2015;20(6):499-514.

20. Wagener M, van Opstal S, Miedema H, Brandjes D, Dahmen R, van Gorp E, et al. Employment-related concerns of HIV-positive people in the Netherlands: input for a multidisciplinary guideline. Journal of occupational rehabilitation. 2014;24(4):790-7.

21. Barroso J, Carlson JR, Meynell J. Physiological and psychological markers associated with HIVrelated fatigue. Clinical Nursing Research. 2003;12(1):49-68.

22. Camlin CS, Neilands TB, Odeny TA, Lyamuya R, Nakiwogga-Muwanga A, Diero L, et al. Patientreported factors associated with reengagement among HIV-infected patients disengaged from care in East Africa. AIDS (London, England). 2016;30(3):495.

23. Barroso J, Hammill BG, Leserman J, Salahuddin N, Harmon JL, Pence BW. Physiological and psychosocial factors that predict HIV-related fatigue. AIDS and Behavior. 2010;14(6):1415-27.

24. Voss JG, Dodd M, Portillo C, Holzemer W. Theories of fatigue: application in HIV/AIDS. Journal of the Association of Nurses in AIDS Care. 2006;17(1):37-50.

25. Schnall R, Cho H, Mangone A, Pichon A, Jia H. Mobile health technology for improving symptom management in low income persons living with HIV. AIDS and Behavior. 2018;22(10):3373-83.

26. Haile TG, Engeda EH, Abdo AA. Compliance with standard precautions and associated factors among healthcare workers in Gondar University Comprehensive Specialized Hospital, Northwest Ethiopia. Journal of environmental and public health. 2017;2017.

27. Adem KS, Janakiraman B, Gebremeskel BF, Chala MB, Gelaw AY, Alemu K. Epidemiology and factors associated with peripheral neuropathy among HIV infected patients in Gondar, Ethiopia: A crosssectional study. PloS one. 2019;14(1):e0211354.

28. Krupp LB, LaRocca NG, Muir-Nash J, Steinberg AD. The fatigue severity scale: application to patients with multiple sclerosis and systemic lupus erythematosus. Archives of neurology. 1989;46(10):1121-3.

29. Valko PO, Bassetti CL, Bloch KE, Held U, Baumann CR. Validation of the fatigue severity scale in a Swiss cohort. Sleep. 2008;31(11):1601-7.

30. Lerdal A, Kottorp A, Gay C, Aouizerat BE, Portillo CJ, Lee KA. A 7-item version of the fatigue severity scale has better psychometric properties among HIV-infected adults: an application of a Rasch model. Quality of Life Research. 2011;20(9):1447-56. 
31. Webel AR, Perazzo J, Decker M, Horvat-Davey C, Sattar A, Voss J. Physical activity is associated with reduced fatigue in adults living with HIV/AIDS. Journal of advanced nursing. 2016;72(12):3104-12.

32. Manea L, Gilbody S, McMillan D. Optimal cut-off score for diagnosing depression with the Patient Health Questionnaire (PHQ-9): a meta-analysis. Cmaj. 2012;184(3):E191-6.

33. McLean E, Cogswell M, Egli I, Wojdyla D, De Benoist B. Worldwide prevalence of anaemia, WHO vitamin and mineral nutrition information system, 1993-2005. Public health nutrition. 2009;12(4):444-54.

34. Sousa VD, Zauszniewski JA, Musil CM. How to determine whether a convenience sample represents the population. Applied Nursing Research. 2004;17(2):130-3.

35. Evans S, Li L. A comparison of goodness of fit tests for the logistic GEE model. Statistics in medicine. 2005;24(8):1245-61.

36. Voss JG, Sukati NA, Seboni NM, Makoae LN, Moleko M, Human S, et al. Symptom burden of fatigue in men and women living with HIV/AIDS in Southern Africa. Journal of the Association of Nurses in AIDS Care. 2007;18(4):22-31.

37. Breitbart W, McDonald MV, Rosenfeld B, Monkman ND, Passik S. Fatigue in ambulatory AIDS patients. Journal of pain and symptom management. 1998;15(3):159-67.

38. Enoka RM, Duchateau J. Translating fatigue to human performance. Medicine and science in sports and exercise. 2016;48(11):2228.

39. Wakeham K, Harding R, Bamukama-Namakoola D, Levin J, Kissa J, Parkes-Ratanshi R, et al. Symptom burden in HIV-infected adults at time of HIV diagnosis in rural Uganda. Journal of palliative medicine. 2010;13(4):375-80.

40. Peltzer K, Phaswana-Mafuya N. The symptom experience of people living with HIV and AIDS in the Eastern Cape, South Africa. BMC health services research. 2008;8(1):271.

41. Schifitto G, Deng L, Yeh T, Evans SR, Ernst T, Zhong J, et al. Clinical, laboratory, and neuroimaging characteristics of fatigue in HIV-infected individuals. Journal of neurovirology. 2011;17(1):17-25.

42. Liu Z, Yang J, Liu H, Jin Y. Factors associated with fatigue in acquired immunodeficiency syndrome patients with antiretroviral drug adverse reactions: a retrospective study. Journal of Traditional Chinese Medicine. 2013;33(3):316-21.

43. Henderson M, Safa F, Easterbrook P, Hotopf M. Fatigue among HIV-infected patients in the era of highly active antiretroviral therapy. HIV medicine. 2005;6(5):347-52.

44. Sullivan PS, Dworkin MS, Adolescent Spectrum of HIV Disease Investigators. Prevalence and correlates of fatigue among persons with HIV infection. Journal of Pain and Symptom Management. 2003;25(4):329-33.

45. Goswami U, Baker JV, Wang Q, Khalil W, Kunisaki KM. Sleep apnea symptoms as a predictor of fatigue in an urban HIV clinic. AIDS patient care and STDs. 2015;29(11):591-6.

46. Belperio PS, Rhew DC. Prevalence and outcomes of anemia in individuals with human immunodeficiency virus: a systematic review of the literature. The American journal of medicine. 
2004;116(7):27-43.

47. Harmon JL, Barroso J, Pence BW, Leserman J, Salahuddin N. Demographic and illness-related variables associated with HIV-related fatigue. Journal of the Association of Nurses in AIDS Care. 2008;19(2):90-7.

48. Voss JG. Predictors and correlates of fatigue in HIV/AIDS. Journal of Pain and Symptom Management. 2005;29(2):173-84.

49. Jong E, Oudhoff LA, Epskamp C, Wagener MN, van Duijn M, Fischer S, et al. Predictors and treatment strategies of HIV-related fatigue in the combined antiretroviral therapy era. Aids. 2010;24(10):1387405.

50. Symptom Burden of Fatigue.pdf.

51. Breitbart W, Mcdonald M V, Rosenfeld B, Monkman ND, Passik S. Fatigue in Ambulatory AIDS Patients. 1998;15(3):159-67.

52. Meynell J, Barroso J. Bioimpedance analysis and HIV-related fatigue. Journal of the Association of Nurses in AIDS Care. 2005;16(2):13-22.

53. Peltzer K, Phaswana-mafuya N. The symptom experience of people living with HIV and AIDS in the Eastern Cape, South Africa. 2008;8:1-8.

\section{Additional Files}

Additional file 1: Criteria to define HIV-associated weight loss

Additional file 2: STROBE statement checklist

\section{Figures}

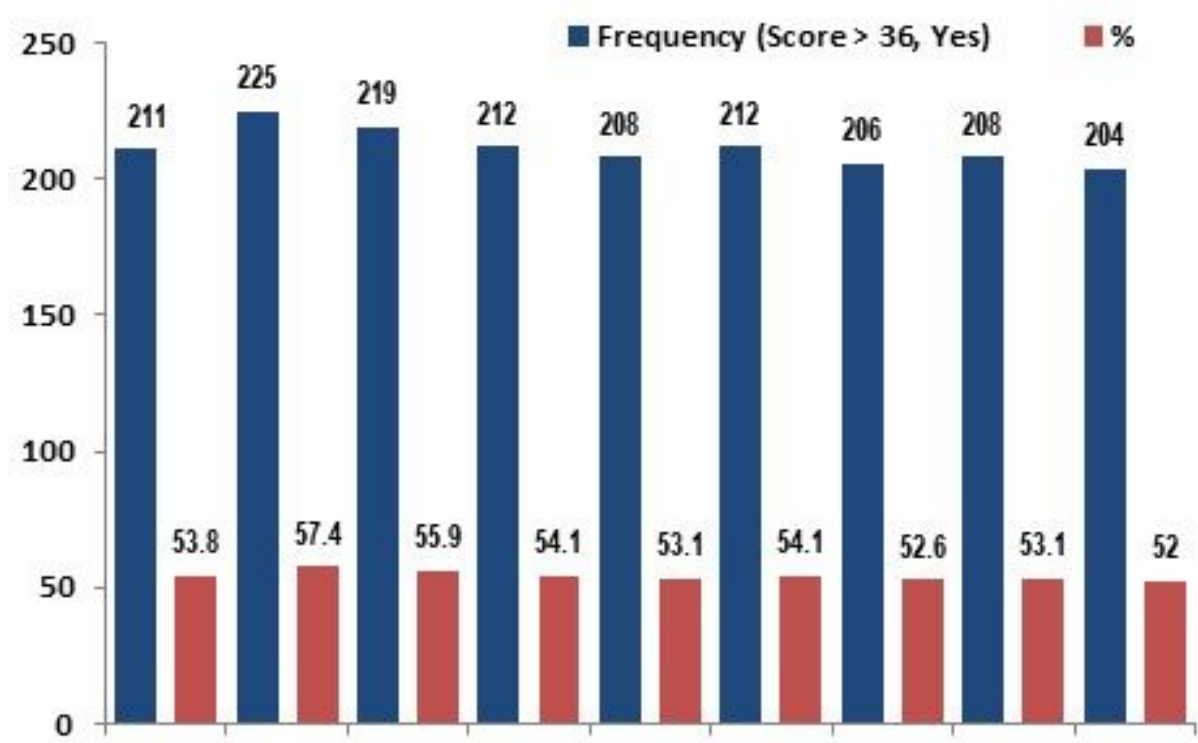

Item-1 Item-2 Item-3 Item-4 Item-5 Item-6 Item-7 Item-8 Item-9 


\section{Figure 1}

Frequency distribution of fatigue characteristics based on 9-item FSS of HIV infected attending ART clinics in the University of Gondar Specialized Comprehensive Hospital, Northwest, Ethiopia 2019 $(\mathrm{n}=392)$. 9-items Fatigue severity scale, Item 1- My motivation is lower when I am fatigued, Item 2Exercise brings on my fatigue, Item 3-I am easily fatigued, Item 4- Fatigue interferes with my physical functioning, Item 5- Fatigue causes frequent problems for me, Item 6- My fatigue prevents sustained physical functioning, Item 7- Fatigue interferes with carrying out certain duties, Item 8- Fatigue is among my three most disabling symptoms, Item 9- Fatigue interferes with my work, family, or social life.

\section{Supplementary Files}

This is a list of supplementary files associated with this preprint. Click to download.

- Additionalfile1.pdf

- Additonalfile2.pdf 